\title{
Evaluation of Water Delivery Performance and Conveyance Efficiency in Gatto Small-Scale Irrigation Scheme, Southern, Ethiopia
}

\author{
Tamirayehu Legesse, Amare Tadesse \\ Faculty of Water Resources and Irrigation Engineering, Arbaminch Water Technology Institute, Arbaminch, Ethiopia
}

Email address:

tamrethiopia@gmail.com (T. Legesse), tadesseame@gmail.com (A. Tadesse)

\section{To cite this article:}

Tamirayehu Legesse, Amare Tadesse. Evaluation of Water Delivery Performance and Conveyance Efficiency in Gatto Small-Scale Irrigation Scheme, Southern, Ethiopia. Journal of Water Resources and Ocean Science. Vol. 10, No. 5, 2021, pp. 139-154.

doi: $10.11648 /$ j.wros.20211005.16

Received: August 25, 2021; Accepted: September 30, 2021; Published: October 28, 2021

\begin{abstract}
Irrigation could serve as a viable solution to address the problem of food insecurity by increasing, boosting agricultural production. This research work was conducted to evaluate the performance of Gatto irrigation scheme using some selected performance indicators specifically, water delivery performance, conveyance efficiency and maintenance indicators of the scheme with in the investigation period of October to December 2017. The discharge measurement was performed at twelve measuring points on main canal and eight at two secondary cannels by using VALEPORT automatic current meter and 3-inch Parshall flumes for each selected nine tertiary offtakes from three each at the head, middle and tail end of the scheme. Water delivery performance evaluated with respect to adequacy, equity, efficiency and dependability was focused on variability in discharges of water distribution from head to tail reach and, during the crop season from October to December with overall average value equal to $0.70,0.44,0.89$ and 0.53 respectively. Thus, the irrigation scheme when compared with Molden and Gates (1990) standards was found under poor condition in adequacy, equity and dependability and under good condition in efficiency. Estimated overall water conveyance efficiencies of the main, first and secondary canals were $86.3 \%, 77.53 \%$ and $73.13 \%$ respectively. However, the result found in the scheme was smaller than FAO (1989b) recommended value (95\%) and (90\%) for lined and unlined cannels with clay soil type. The design depth of water based on the design document was $0.42 \mathrm{~m}$ nevertheless the actual depth of water in the main canal was $0.26 \mathrm{~m}$ due to this the relative change of the water level was $38.1 \%$ this greater than 0 value indicates that the intended water level in the main canal has not been achieved due to sediment accumulation in the canal. The result of Gatto small scale irrigation scheme of effective of infrastructures is reckoned to be 57.2 percent and sustainability of irrigation scheme is $88 \%$. Many of the structures are demolished and became dysfunctional because of scouring, sedimentation and silt accumulation. Generally, the performance of the system is poor, it mainly results due to inadequate operation and maintenance provisions and over abstraction of water by upstream users. Therefore, adequate maintenance and other suitable management and operation approaches are required to improve the irrigation system performance. So, all stakeholders must work together in order to minimize factors that hinder the good performance of the irrigation system.
\end{abstract}

Keywords: Conveyance Efficiency, Equity and Adequacy, Gatto Small Scale Irrigation Scheme, Performance, Water Delivery

\section{Introduction}

Irrigation could serve as a viable solution to address the problem of food insecurity by increasing, boosting agricultural production. Based on this evidence, in Ethiopia and in other parts of the world, large, medium and small- scale irrigation schemes have been constructed and made available for increasing agricultural production and productivity. According to [19] complained that 'the initial plans for many of irrigation projects in developing countries have focused almost exclusively on engineering designs for the physical systems. To give the required purpose it is true 
that the management aspect of irrigation must be taken in to account. Delivery of water for farmers and subsequent maintenance were frequently not addressed [21].

In our country the poor performance of small-scale irrigation scheme is existed; however, the frequent assessment is not common, and also resource management challenges are often observed in small scale irrigation systems [22]. The performance of many irrigation systems is significantly below their potential due to a number of limitations; including poor design, construction, operation, maintenance, and ineffective water control and measurement structure installation [16].

There are some problems, which hampered water resource utilization: insufficient supply, siltation, wastage in some areas and uneven distribution in terms of time and place [8]. According to [6], the wider objectives of performance assessment are: to upgrade management capabilities in both public and private sector irrigation and drainage projects with a view to improving the efficiency with which available resources are used. To assess the performance of irrigation scheme different researchers used the internal and external indicators; according to [4] water delivery performance indicators are one of the internal indicators used to facilitate the analysis of irrigation water delivery system in terms of adequacy, efficiency, dependability, and equity of water delivery. Frequent monitoring of the performance of the irrigation system assists to distinguish whether the targets and requirements are being met or not [10].

Unsatisfactory performance of irrigation system in the country is associated with little experience in irrigation is not the only consequence of technical deficiencies in the design of the system, but also many of the problems stem from weaknesses in the organization and management of the system.

The supply and distribution of irrigation water are most often not adequate, equitable and reliable which is a primary essential condition that will limit to achieve the highest productivity [1].

In Gatto irrigation scheme, there are poor irrigation water management practices leads to inefficient water distribution and non-uniform crop growth, all of these decrease the yield per unit of the land area against per unit water applied. The water user located at the upstream of the irrigation system get more water than those located at the downstream of the system.

In this irrigation system, the tail end users are seriously affected in water scarce period. No comprehensive performance evaluation of the scheme has been done so far. In view of these problems of water control and delivery in the scheme, it became essential to evaluate the performance and operation of the scheme by using performance indicators.

\section{Materials and Methods}

\subsection{Study Area Description}

This study was conducted in Derashe woreda which was found in the South Nationality Peoples of Regional State in Segen zone. It is endowed with natural forests, rivers, tourist attraction sites, minerals, crops, strong working culture, wildlife, and others. The total land area of the woreda is 1532 $40 \mathrm{SKm}^{2}$. Topographically the woreda lies between 501-2500 meters above sea level. The total population of the woreda is about 133, 543 (2007). Gatto irrigation schemes were managed by communities which were found in Derashe woreda Gatto Kebele on Yanda River and $10 \mathrm{Km}$ a part from Gidole town in southeast and the diversion structure which initially deigned to irrigate 200 ha but currently the command area is 176 ha.

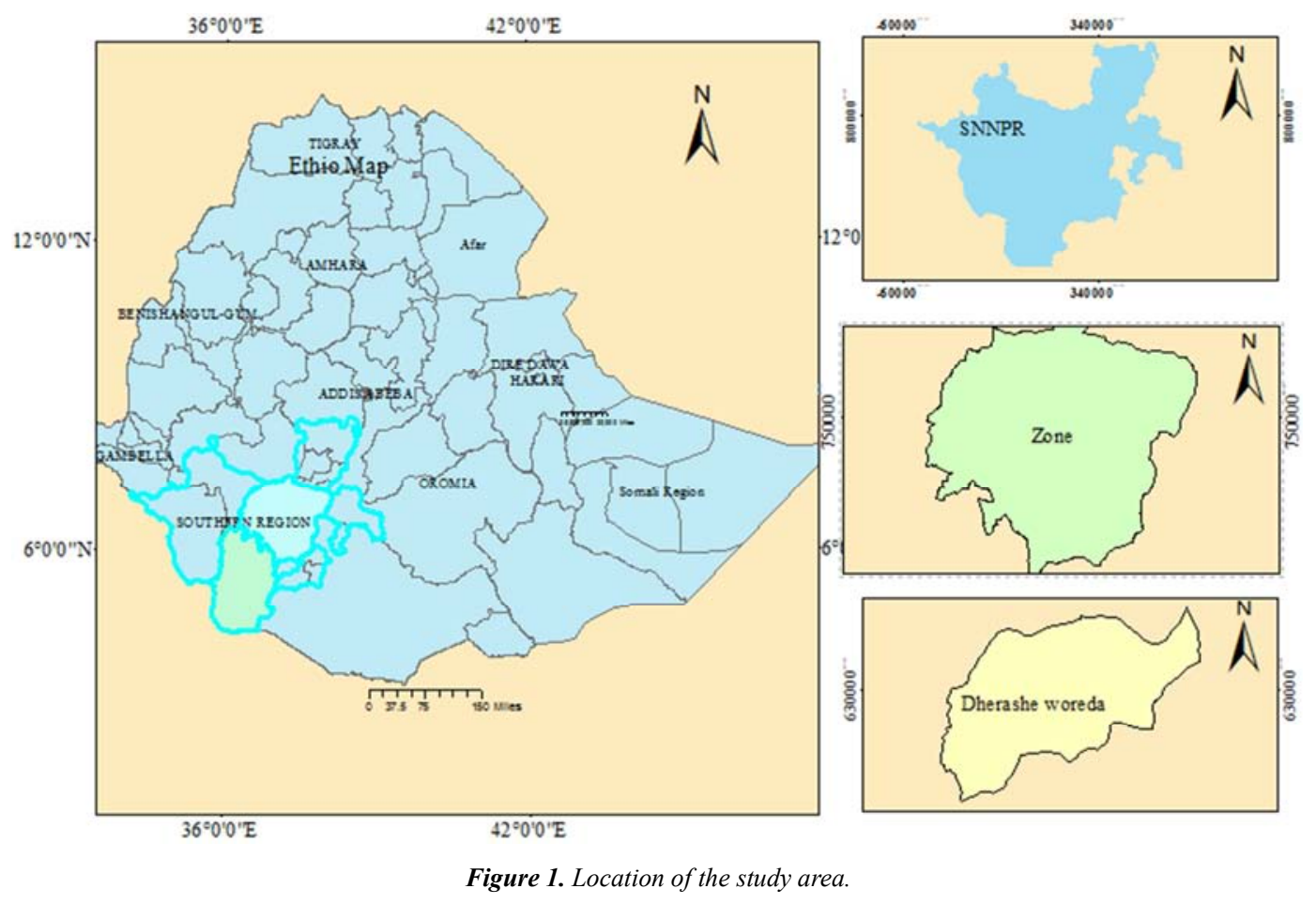




\subsection{Data Collection}

The data collection had been carried out in collaboration with Das in the Kebele, the Woreda Agricultural office expert and some farmers were consulted and respective organizations through formal and informal interview with the aid of questionnaire and physical measurement and/or observation. statistical measures such as mean, standard deviation, coefficient of variation have been used for the analysis.

\subsubsection{Secondary Data}

The secondary data were collected from different sources. The data collected from the secondary sources include necessary documents, studies and other useful written materials needed for the study. Organizations contacted during the study period were, regional water works enterprise, Zonal Bureau of Agriculture, Zonal Bureau of Water Resources Development, Derashe woreda Agricultural office and Zonal Bureau of metrological agency. The secondary data included design and layout of the scheme, design of conveyance and water control structures, irrigated area, area irrigated per crop per season/year, crop types, cropping pattern and the role of irrigation water user's association. Based on farmers questionnaire developed interview were made to identify key constraints of scheme performance including view of the farmers about the water supply and distribution, water control structures, rainfall amount and distribution in the past years, and allow priorities to be established.

A number of farmers have been selected from each location to provide information on the water delivery performance problems of the scheme, conveyance efficiency of the scheme and maintenance conditions of the scheme. The total of $10 \%$ farmers are randomly selected based on location relative to the canals as head, middle and tail end users. Much effort has been made through field measurement and observations of different documents at different places to check the reliability and consistency of these data. Based on survey analysis there were about 171 households benefiting from the project from 176 ha irrigated land. The scheme is managed by different "Yewuha Abats". Selected from each block and they are accountable to Kebele leaders.

\subsubsection{Primary Data}

Field investigations were taken to assess both the structural integrity of system components and their fitness to control and/or convey flows. Measurements were made to evaluate irrigation water applied to the field by the use of instrument like three-inch Parshall flume, depth of water infiltrated during irrigation events measurements were taken by using double infiltrometer, soil moisture content two days before and after irrigation events and observations have been made how farmers control and manage irrigation water during application/irrigation events. Beneficiary households were also randomly interviewed to know their perception on scheme performance and institutional aspects.

\subsection{Materials Used}

To perform this study the following material were used those are, Tape meter: was used to measure the length of the canal, Stop watch: to know the time taken water passing through the Parshall flume and current meter, Osk 1041 prices' electric Current meter: used to measure flow velocity in the conveyance system. 3-inch Partial flume: used to measure the depth of water or discharge at field level, GPS: was used take the coordinates of the study area and Soil auger was used to collect soil sample at different soil sample depth. Survey data were analyzed using qualitative description and descriptive statistic. Close ended questions were analyzed using Statistical Package for the Social Sciences version 20.0 (SPSS). Monthly recorded flow data were analyzed with excel sheet, the required discharge was estimated using CROPWAT 8.0 windows computer program and the study area was delineated with GIS software.

\subsection{Soil Data Analysis}

As shown in figure 2. Soil samples were collected to determine soil moisture content, soil textural class, bulk density, field capacity, permanent wilting point of the soil from irrigated fields at depth interval of $20 \mathrm{~cm}$ to maximum of $60 \mathrm{~cm}$ depth. Samples were taken before and 2 days after irrigation events. This depth was considered as effective root zone of the crops at the time of measurement. The soil samples were placed in containers of known weight and then weighed. The samples were dried in an oven for 24 hours at temperature of $105^{\circ} \mathrm{C}$ with the containers cover removed. After drying, the soil and container were again weighed and the weight of water determined as following pre and post readings. The dry weight fraction of each sample was calculated using the equation [13].

$$
\Theta \mathrm{w}=\frac{W w-W d}{W d} * 100
$$

Where: $\theta \mathrm{w}=$ Soil water content on a dry weight basis [\%]

$\mathrm{Ww}=$ Wet weight of the soil $[\mathrm{gm}]$

$\mathrm{Wd}=$ Dry weight of the soil [gm]

Then the moisture contents of the soils collected from the selected fields at different depths were determined. To convert the dry weight soil moisture fraction into volumetric moisture content the dry weight fraction $(\theta w)$ was multiplied by its respective bulk density $(\rho b)$ and divided by the specific weight of water ( $\rho w)$ as follows;

$$
\begin{aligned}
& =\frac{\rho \mathrm{b} * \mathrm{w}}{\rho \mathrm{w}} \\
& \rho \mathrm{b}=\frac{M s}{V c}
\end{aligned}
$$

Where,

$\rho b=$ soil bulk density $\left(\mathrm{g} / \mathrm{cm}^{3}\right)$,

$\mathrm{Ms}=$ weight of dry soil $(\mathrm{g})$, and

$\mathrm{Vc}=$ volume of core sampler $\left(\mathrm{cm}^{3}\right)$ 


$$
\operatorname{TAW}(\mathrm{mm})=100 *(\mathrm{\Theta FC}-\mathrm{\Theta PWP}) * \mathrm{Zr}
$$

Where TAW $=$ total available water in the root zone $(\mathrm{mm})$, $\theta \mathrm{FC}=$ moisture content at field capacity $\left(\mathrm{m}^{3} / \mathrm{m}^{3}\right)$, $\Theta \mathrm{PWP}=$ the moisture content at permanent wilting capacity $\left(\mathrm{m}^{3} / \mathrm{m}^{3}\right)$ $\mathrm{Zr}=$ the root depth $(\mathrm{m})$

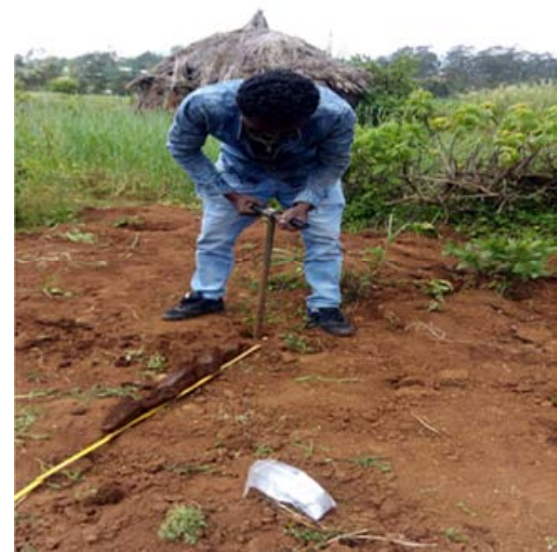

Figure 2. Soil sample from the farmers plot using augur.

\subsubsection{Field Capacity and Permanent Wilting Point Determination}

Soil samples were collected from the field for laboratory analysis, the soil samples were analyzed for field capacity (FC) and permanent wilting point (PWP) using pressure plate apparatus at $1 / 3$ and 15 bar, respectively. Soil samples were taken to the laboratory From Head Middle Tail in the field per plot. Soil samples were taken before irrigation and two days after irrigation from $0-20 \mathrm{~cm}, 20-40 \mathrm{~cm}$ and $40-60 \mathrm{~cm}$ depths per test pit. From each irrigated farm 9 samples out of 3 auger holes were taken. At a depth interval of $20 \mathrm{~cm}$ up to $60 \mathrm{~cm}$ were taken from each hole. Total available water (TAW) which is an estimate of the amount of water a crop can use from the soil for the selected fields was computed from the moisture content in volume percent at field capacity and permanent wilting point [2].

\subsubsection{Infiltration Measurement}

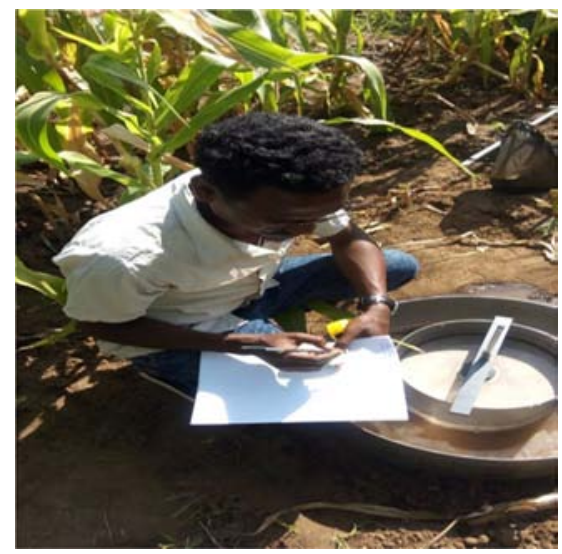

Figure 3. Infiltration measurement at plot by using double infiltrometer.

As shown in figure 3. The measurement of infiltration rate was conducted using double ring infiltrometer at three random points of the experimental plot. The output of infiltration rate data was used as an input to the CROPWAT 8 computer model in determining irrigation scheduling. The inner and outer rings of the infiltrometer are 30 and $40 \mathrm{~cm}$ diameters respectively. Both rings were driven into $15 \mathrm{~cm}$ soil depth by hammering wooden plank placed on the top of them. Infiltration measurement was taken continuously until the infiltration of the soil reach constant.

\subsection{Crop Water Requirement and Irrigation Water Requirement}

Determination of crop water requirements is needed to know how much of the applied irrigation water is consumed by the crop. The crop water requirement (CWR) of the major irrigated crops grown in the irrigation scheme was estimated using CROPWAT 8.0 windows computer program. The determination of the CWR by the model depends on the determination of the reference evapotranspiration value using the available climatic data. The twenty-nine years mean climatic data for the nearest station (Arguba) was used. Data for major crops grown in the study areas such crops were Maize, Sorghum and Onion including growing stages and stage lengths (days), crop coefficients (Kc), rooting depths $(\mathrm{Zr})$, depletion levels $(\mathrm{P})$, yield response factors $(\mathrm{Ky})$ and planting date were obtained from FAO guidelines [11,2].

The first step is determining crop evapotranspiration (ETc.) that is essential for computing the soil water balance and irrigation scheduling. It is governed by weather and crop condition. The procedures to estimate ETc from ET0 us in $\mathrm{f}$ (Kc) value has been well established by [11] as expressed by Equation (5) and irrigation water requirement expressed in question (6).

$$
E T c=K c * E t o
$$

Where;

$\mathrm{ETc}=$ Crop water requirement

$\mathrm{Kc}=$ crop coefficients

$$
I R=E T c-P e
$$

Where:

Ir is Irrigation water requirement

ETc is crop evapotranspiration ( $\mathrm{mm} /$ season),

Peff $=$ effective rainfall $(\mathrm{mm} /$ season $)$.

$\mathrm{ETo}=$ reference crop evapotranspiration

Crop evapotranspiration (ETc) refers to evapotranspiration of a disease-free crop, grown in very large fields, not short of water and nutrient.

\subsection{Flow Measurement}

As shown in figure 4 for the purpose of flow measurement calibrated Parshall flumes of the standard size were used. To determine the amount of water applied by the irrigators to the field, during an irrigation event, automatic calibrated three inches (3") Parshall flumes were installed at the entrance of test plot. Frequent readings were taken when the farmers 
irrigate the test plot. Irrigation was continuing until the farmers' thought that enough amount of water is applied to the field. When the irrigator completed irrigating the test plot, the average depth of irrigation water passing through the flume and the respective discharge were read for the sizes of test plot being irrigated. The discharge and the depth of water applied were recorded automatically.

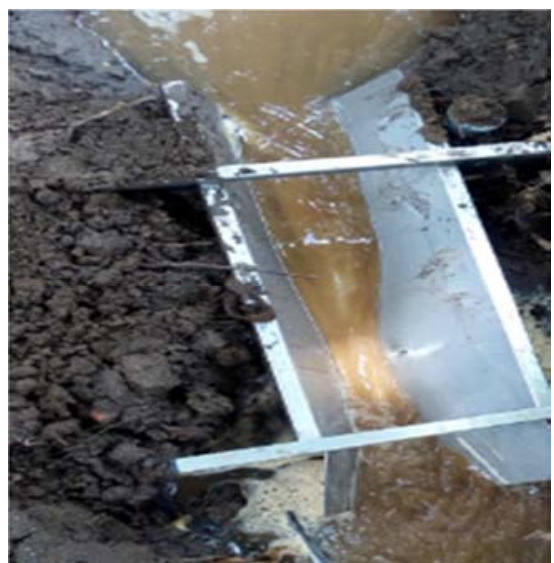

Figure 4. Infiltration measurement at plot by using double infiltrometer.

\subsection{Delivery Performance Indicators}

\subsubsection{Adequacy}

According to [5] all indicators that deal with adequacy have to include some estimation of demand. Demand may be based solely on technical criteria, such as evapotranspiration demand for particular crops or cropping patterns, it may include soil water requirements such as those used for estimating land preparation water requirements, and it may include water lost through natural seepage and percolation.

During the three-month study period adequacy was determined for a service area $(\mathrm{R})$ averaged over time period of consideration ( $\mathrm{T}$ ) that was temporal variability of the scheme and determined at Head, Middle and Tail of the scheme.

Adequacy indicator (PE) was determined by the formula (Molden and Gates, 1990) is expressed by Equation (7).

$$
P A=\frac{1}{T} \sum_{T} *\left(\frac{1}{R} \sum_{R} P A\right)
$$

If $\mathrm{QD} \leq \mathrm{QR}$, otherwise $\mathrm{PA}=1$,

Where, $\mathrm{PA}=\mathrm{QD} / \mathrm{QR}$

$\mathrm{PA}$ is adequacy performance indicators,

$\mathrm{T}$ is time and $\mathrm{R}$ is site where canals are located,

QD is actual amount of water delivered by the system and

QR is the amount of water required for crop consumptive use.

\subsubsection{Equity}

Equity expresses the degree of variability in relative water delivery from point to point over the irrigated area [14]. A measure of equity would be the average relative spatial variation of the ratio of the amount delivered to the amount required over the period of interest as given by Equation (8).

$$
P E=\frac{1}{T} \sum_{T} C V R\left(\frac{Q D}{Q R}\right)
$$

Where, CVR is spatial coefficient of variation of the ratio $Q D$ to $Q R$ over the region $R$. Closer the value of $P E$ is to zero, greater the degree of equity in delivery. Performance was said to be good when the value of PE was between 0.00 and 0.10 , fair when it was between 0.11 and 0.25 , and poor when it was more than 0.25 .

\subsubsection{Dependability}

It is defined as the temporal uniformity of the ratio of the delivered amount of water to the required or scheduled amount. Dependability expresses the ability to find water at the time desired and in the place desired in the system, as well as the degree of the temporal variability of the irrigation delivery in comparison with the requirements. In this respect, dependability comes to mean that the water can be delivered at the promised flow rate and duration. This performance measurement indicates the uniformity of (QD/QR) over time. An irrigation system which achieves almost steady water distribution is considered to be dependable. The dependability parameter is expressed as by Equation (9).

$$
P D=\frac{1}{R} \sum_{R} C V T\left(\frac{Q D}{Q R}\right)
$$

Where

$\mathrm{PD}$ is dependability indicator over a time period $\mathrm{T}$ for a region $\mathrm{R}$, and CVT is the temporal coefficient of variation (ratio of standard deviation to mean) of the ratio (QD/QR) over the discrete location in a region $\mathrm{R}$ and a time period $\mathrm{T}$. QD is delivered amount of water over an area $\mathrm{R}$ and time $\mathrm{T}$. $\mathrm{QR}$ is required amount of water over an area $\mathrm{R}$ and time $\mathrm{T}$. As the value of PD approaches zero, the relative water delivery is becoming more uniform over time, indicating a more dependable delivery.

\subsubsection{Efficiency}

Efficiency is defined as the ratio of the volume of water required for a specific purpose to the volume of water delivered for this purpose. It is commonly interpreted as the volume of water stored in the soil for evapotranspiration compared to the volume of water delivered for this purpose $[17,3]$.

System managers should always be thoughtful that the water delivered should not be greater than the requirement. If the system is supplying more than the requirement, it indicates the non-conservation of the resources. A measure of this would be the spatial and temporal average of the ratio of QR to QD. Efficiency embodies the ability to conserve water by matching irrigation application with crop water requirements as given by Equation (10).

$$
P F=\frac{1}{T} \sum_{T}\left(\frac{1}{R} \sum_{R} P F\right)
$$

Where: PF is the special and temporal average of the ratio $\mathrm{QR} / \mathrm{QD}$ indicator over an area $\mathrm{R}$ and time period $\mathrm{T}$ for a specific time. 


$$
\mathrm{PF}=\frac{Q R}{Q D}(\mathrm{IF} \mathrm{QR} \leq \mathrm{QD})
$$

Otherwise, $\mathrm{PF}=1$

If $\mathrm{pF}$ was equal to or close to 1.00 , this meant that water in the system was being used efficiently, but if the value was less than 0.70 , it meant that water in the system was not being used efficiently. Performance was said to be good when the value of PF was between 0.85 and 1.00 , fair if it was between 0.70 and 0.84 , and poor if it was below 0.70 the acceptable value were indicated in table 1 .

\subsection{Scheme Performance Evaluation}

To evaluate the conveyance efficiency, delivery performance and maintenance measures of the scheme under the maximum required flows, the design discharges represent a base line for comparison. The discharge, depth and width of the channel at the estimated discharge were compared with design values at full discharge.

\subsection{Conveyance Efficiency}

The conveyance efficiency and conveyance loss were determined by direct measurement taken with automatic current meter and readings were taken at different location of primary and secondary canal reach. With the interval of $100 \mathrm{~m}$ far from the source up to the end of canal reach. Then the conveyance loss in the specified length of canal reaches and the effective conveyance $(\mathrm{Ec})$ ratio that represents the capability of a canal reach to carry water with loss were computed using equations (11),[9]:

$$
\begin{gathered}
E c=\frac{\text { Qout }}{\text { Qin }} * 100 \\
\mathrm{~L}=\mathrm{Q}_{\text {in }}-\mathrm{Q}_{\text {out }}
\end{gathered}
$$

Where; $\mathrm{L}=$ is conveyance loss;

Qin and Qout are the inflow and out flow in specified canal reach and $\mathrm{E}_{\mathrm{C}}=$ effective conveyance ratio that represents the capability of a canal reach to carry water with loss measurement points were located in areas where there is no inflow from other sources to the conveyance system and no other deliveries from the conveyance system.

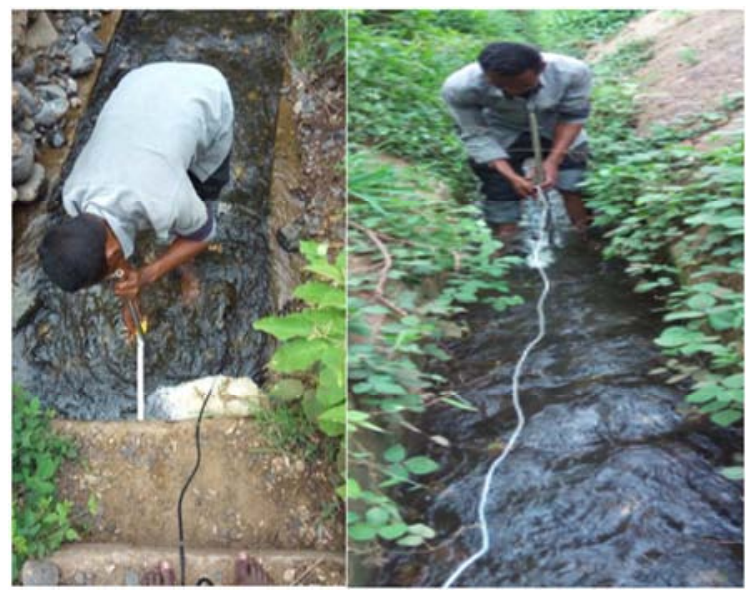

Figure 5. Flow Measurement at Main Canal by using current meter.
The discharges were calculated from the velocities of the water flowing in the main canal using automatic reading Current meter (Osk 1041 prices' electric Current meter) (Figure 5). The first control point measurement of discharge was conducted $40 \mathrm{~cm}$ far from the intake and the other measurements have been taken $100 \mathrm{~m}$ interval consecutively. In this location, the cross-section of the canal was lined, uniform and rectangular in shape as seen in Figure 5.

\section{Results and Discussions}

\subsection{Irrigation Water Distribution System}

In Gatto irrigation scheme, Irrigation management is carried out in rotation among the groups in which the farmers are free to irrigate till they have received enough water. There is irregular irrigation interval in the scheme which varies from 7 to 10 days depending on the growth stage of crops. Regarding scheduling, all the groups get water turn by turn and the method of water distribution here is also a rotational type. The farmers are organized in different teams in the scheme so the next irrigation turn will be repeated after all the teams have fully irrigated their farm. The availability of water for upstream and downstream farmers is not the same, i.e., there is a loss of water in the scheme.

The irrigation interval in the initial period of the crops commonly grown in the area is about 6 days; while it increases 7 to 10 days at the end of the growing season. Some farmers irrigate according to the schedule but other farmers negotiate with other groups to use more or earlier irrigation water. If such farmers are granted water, then they usually have to wait until all the group members with the right to irrigate finish irrigation, after which they can irrigate their own fields.

The diversion structure was constructed by the Lutheran NGO organization for the purpose of keeping food security of the area. The main canal length is about $1.2 \mathrm{~km}$ and constructed in lined masonry. Despite some breaching of canals by illegal users, hydraulically the structure was under good condition. There are two secondary canals and the first canal is $750 \mathrm{~m}$ and the second canal is the length of $600 \mathrm{~m}$ and both secondary canals are unlined. In the irrigation scheme, there was traditionally constructed siphon structure and cannel to pass irrigation water safely.

\subsection{Soil Analysis}

To investigate some of the physical properties of soil in the site (texture, bulk density, moisture content at field capacity (FC) and permanent welting point (PWP), moisture content before and after irrigation), for the purpose of understanding the general feature of the irrigated soil type, different field observations were taken and analyzed. The result is presented and discussed as follows.

\subsubsection{Particle Size Distribution (Texture)}

Samples of soil were taken for the analysis of soil texture, 
bulk density, field capacity and wilting point. The sampling points for the analysis of each parameter were distributed over the scheme so that most parts of the fields are represented. The compositions were defined by the use of USDA textural triangle. Based on laboratory analysis of particle size distribution, the textural class was found to be heavy clay at all depths.

\subsubsection{Field Capacity, Permanent Wilting Point and Bulk Density}

The bulk density of soil of the area showed a variation with depth varied between 1.13 to $1.41 \mathrm{~g} / \mathrm{cm}^{3}$ and generally the top surface soil had lower bulk density than the subsurface. The top $0-20 \mathrm{~cm}$ had an average bulk density of $1.23 \mathrm{~g} / \mathrm{cm}^{3}$ whereas; the subsurface $(20-40 \mathrm{~cm})$ and $(40-60 \mathrm{~cm})$ had an average bulk density of 1.38 and $1.36 \mathrm{~g} / \mathrm{cm}^{3}$ respectively. Generally, the weighted average bulk density of the soil in the experimental station was found to be 1.33 $\mathrm{g} / \mathrm{cm}^{3}$.

The moisture content at the field capacity varied with depth between $29.4 \%$ and $52.6 \%$ with average value of $40.54 \%$ on volume basis. The top $0-20 \mathrm{~cm}$ soil has average FC value of $40.74 \%$ ranging between $33.0 \%$ and $52.5 \%$. Similarly, the sub surface soils have FC value between $29.4 \%$ and $52.6 \%$ with average value of $40.45 \%$. The moisture content at permanent wilting point also showed variation with depth ranging between $18.8 \%$ and $36.4 \%$ with average value of $26.3 \%$ on volume basis. The top layer has an average PWP value of $26.64 \%$ whereas the subsurface soil. $26.14 \%$ the total available water (TAW) is directly related to variation in FC and PWP.

\subsubsection{Infiltration Characteristics of the Soil}

To estimate infiltration characteristics of the soils, field experiment for the measurement of soil infiltration rate was conducted using three sets of infiltration rings for each selected farms at head, middle and tail. The scheme average basic infiltration rate was $4.5 \mathrm{~mm} / \mathrm{hr}$. A typical infiltration characteristic curve of the soil is shown in Figure 6. According to [12] corporative document repository, soils having the basic infiltration rate between $1-5 \mathrm{~mm} / \mathrm{hr}$ are categorized as clay. The result is used for an input data for CROPWAT model.

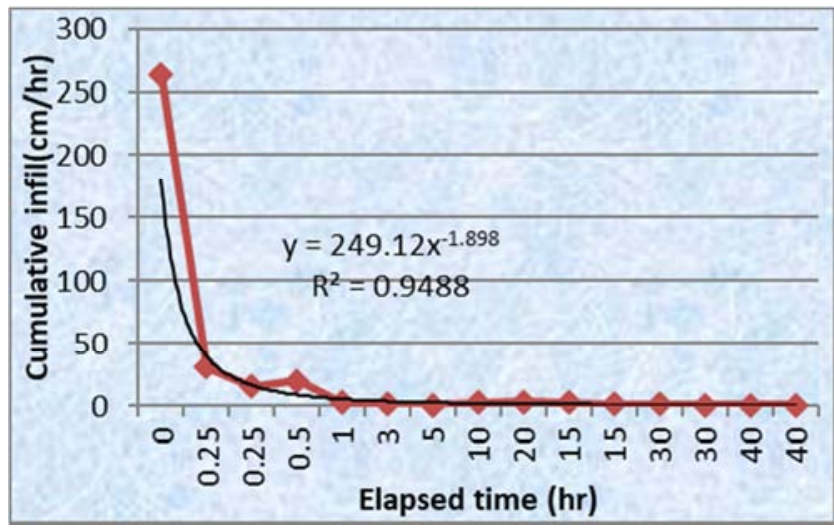

Figure 6. Typical infiltration characteristic of the soil of the study area.

\subsection{Crop Water and Irrigation Requirements}

\section{Rainfall data analysis}

Twenty-nine years of Rainfall data were collected from Arguba metrological station near to the scheme and it has the same Agro-climatic condition with the study area, hence; there is no any meteorological station in the schemes. The average total annual rainfall of the study area is $878.1 \mathrm{~mm}$ and the average total annual effective rainfall amount of the study areas is $742.6 \mathrm{~mm}$.

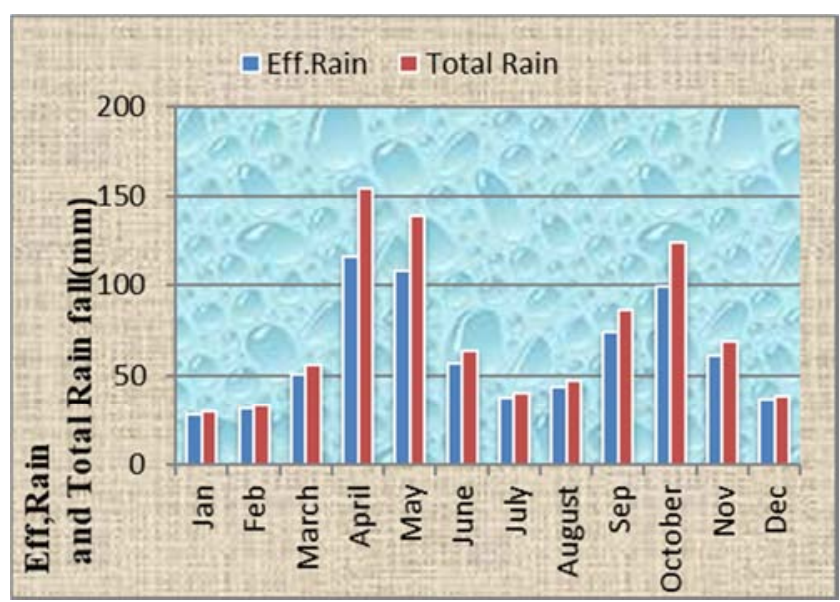

Figure 7. Effective rain falls and Total rainfall ( $\mathrm{mm}$ )

\subsection{Determination of Crop Water and Irrigation Requirement of the Crops}

The average 29 years climatic data were used for computing the crop water requirement. The water requirement of the major crops grown in the irrigation project were determined using CROPWAT 8 computer model based on the irrigation intervals of each crop as practiced by the farmers at each plot presented on Stage days basis and the major crops selected for this study were, Maize, Onion and Sorghum from Head, Middle and Tail reaches this has been done from each nine tertiary off takes were selected.

The water requirement (ETc) of major crops of the study areas were calculated using crop coefficient approach on the basis of meeting the evapotranspiration rate of a disease-free crop, growing in large field under optimal soil conditions including sufficient water and fertility and achieving full production potential under the given growing environment. The analysis indicates that during the cropping season, irrigation was required continuously, though there was variation in the amount.

The computation result using the software indicated that a total crop water requirement of onion was $309.9 \mathrm{~mm} / \mathrm{dec}$ and effective rainfall was $176.9 \mathrm{~mm} / \mathrm{dec}$. The total net irrigation water required over the growing period of onion was $149.4 \mathrm{~mm} / \mathrm{dec}$. The peak irrigation demand of the onion crop was found to be $31.2 \mathrm{~mm}$. The amount of peak irrigation demand of Maize crop was $38.2 \mathrm{~mm} / \mathrm{Dec}$. The total crop water requirement for the growing period of maize was $390.3 \mathrm{~mm} / \mathrm{de}$ and the effective rainfall, expected to be available for plants use, was $215.4 \mathrm{~mm} / \mathrm{dec}$. Therefore, the total net irrigation water requirement necessary to fill this gap was $293.6 \mathrm{~mm}$. 
Table 1. Reference crop evapotranspiration of onion.

\begin{tabular}{|c|c|c|c|c|c|c|c|}
\hline \multirow{2}{*}{ Month } & Min Temp & Max Temp & Humidity & Wind & Sunshine & Radiation & ETo \\
\hline & ${ }^{\circ} \mathrm{C}$ & ${ }^{\circ} \mathrm{C}$ & $\%$ & km/day & Hours & $\mathrm{MJ} / \mathrm{m}^{2} / \mathrm{day}$ & $\mathrm{mm} / \mathrm{day}$ \\
\hline January & 16.3 & 32.2 & 49 & 46 & 8.9 & 21.3 & 3.96 \\
\hline February & 16.9 & 33.3 & 45 & 52 & 8.7 & 22.1 & 4.33 \\
\hline March & 18.4 & 33.4 & 49 & 58 & 8.3 & 22.3 & 4.62 \\
\hline April & 18.3 & 30.9 & 62 & 55 & 7.6 & 21.1 & 4.35 \\
\hline May & 18.2 & 29.1 & 66 & 57 & 7.6 & 20.4 & 4.11 \\
\hline June & 17.4 & 27.3 & 61 & 60 & 6.8 & 18.8 & 3.72 \\
\hline July & 17.9 & 28 & 61 & 58 & 4.9 & 16.1 & 3.37 \\
\hline August & 18.1 & 28.8 & 59 & 65 & 5 & 16.8 & 3.6 \\
\hline September & 17.5 & 29.1 & 56 & 61 & 6.9 & 20 & 4.06 \\
\hline October & 16.8 & 28.9 & 61 & 47 & 7.5 & 20.4 & 3.94 \\
\hline November & 15 & 29.6 & 56 & 38 & 8.4 & 20.7 & 3.79 \\
\hline December & 13.8 & 30.2 & 48 & 43 & 9 & 21 & 3.69 \\
\hline Average & 17.1 & 30.1 & 56 & 53 & 7.5 & 20.1 & 3.96 \\
\hline
\end{tabular}

\subsection{Performance Evaluation}

The performance of a system is a measurement of the gradation/level of fulfillment of the recognized objectives. Such a degree is distinct by a number of parameters chosen as evaluation criteria or indicators [20,7]. The tool helps to improve the level of service and to improve the efficiency with which resources are being used [5]. The results of this study have been discussed in the following section. Three reference values were used to investigate the performance of the system (i.e., actual, required and intended values) including: the actual and required discharge of the main and secondary canals, the irrigated area and total command area, duration of water supply; functional, malfunctioned and total structures of the irrigation system were used.

\section{Determination of Water Required and Water Delivered}

The different delivery performance indicators were estimated for each field off takes and reach wise (head, middle, and tail) for three months from October to December, in one irrigation season there are different types of crops were grown. Crop Water Requirement and Irrigation Water requirement section. Monthly crop water requirement of all those crops was calculated by cropwat model 8 , effective rainfall was deducted from the corresponding month and the average was used. After calculating average crop water requirement by multiplying, it with the command area at each branch offtake canals, the monthly irrigation water required was as shown on table 2 .

Table 2. Estimated values of required $(Q R)$ and delivered flow $(Q D)$.

\begin{tabular}{|c|c|c|c|c|c|c|c|c|c|c|c|}
\hline \multirow{2}{*}{ Reach } & \multirow{2}{*}{$\begin{array}{l}\text { off } \\
\text { take }\end{array}$} & \multirow{2}{*}{$\begin{array}{l}\text { crop } \\
\text { type }\end{array}$} & \multirow{2}{*}{$\begin{array}{l}\text { area of } \\
\text { filed (ha) }\end{array}$} & \multicolumn{2}{|l|}{ Oct. } & \multicolumn{2}{|l|}{ Nov. } & \multicolumn{2}{|l|}{ Dec. } & \multirow{2}{*}{$\begin{array}{l}\text { Temporal Mean } \\
\text { of } Q R(1 / s)\end{array}$} & \multirow{2}{*}{$\begin{array}{l}\text { Temporal Mean } \\
\text { of } Q D(1 / s)\end{array}$} \\
\hline & & & & QD & QR & QD & QR & QD & QR & & \\
\hline \multirow[t]{4}{*}{ Head } & TO1 & Onion & 1.6 & 3.46 & 3.12 & 2.93 & 3.6 & 8.11 & 8.5 & 5.07 & 4.83 \\
\hline & TO2 & Maize & 12.5 & 2.29 & 1.97 & 1.17 & 2.34 & 6.1 & 3.8 & 2.72 & 3.19 \\
\hline & TO3 & Sorghum & 9 & 2.28 & 1.6 & 0.38 & 3.17 & 13.54 & 4.9 & 3.24 & 5.40 \\
\hline & Mean & & & 2.68 & 2.23 & 1.49 & 3.04 & 9.25 & 5.76 & 3.68 & 4.47 \\
\hline \multirow[t]{5}{*}{ Middle } & TO4 & Maize & 14.6 & 5.66 & 3.14 & 0.91 & 4.8 & 3.5 & 11 & 6.43 & 3.36 \\
\hline & TO5 & Maize & 5.5 & 5.19 & 3.6 & 1.66 & 4.12 & 11.2 & 9.7 & 5.82 & 6.02 \\
\hline & TO6 & Onion & 4.5 & 1.88 & 3.08 & 2.78 & 3.7 & 8.01 & 8.4 & 5.06 & 4.22 \\
\hline & Mean & & & 4.24 & 3.27 & 1.78 & 4.21 & 7.57 & 9.82 & 5.77 & 4.53 \\
\hline & TO7 & maize & 10.4 & 3.08 & 3.6 & 0.34 & 4.16 & 8.96 & 9.8 & 5.86 & 4.13 \\
\hline \multirow[t]{3}{*}{ Tail } & TO8 & Onion & 2.6 & 0.03 & 0.95 & 0.65 & 1.13 & 1.29 & 1.8 & 1.28 & 0.66 \\
\hline & TO9 & Sorghum & 8.5 & 3.29 & 1.7 & 2.62 & 3.4 & 2.25 & 5.1 & 3.40 & 2.72 \\
\hline & Mean & & & 2.13 & 2.08 & 1.20 & 2.90 & 4.17 & 5.57 & 3.52 & 2.50 \\
\hline
\end{tabular}

$\mathrm{TO}=$ tertiary offtake canal at head, middle, and tail water delivery performance levels were evaluated on spatial and temporal scales. The spatial indicators are meant for the water delivery performance over a region $\mathrm{R}$; while the temporal indicators are for the water delivery performance in time $\mathrm{T}$.

\subsection{Water Delivery Performance}

Water delivery performance indicators that listed by [18] was used at nine measuring location (Head, Middle and Tail) for Three months from October to December.

Those indicators are adequacy (delivery of required amount) PA, efficiency (Conservation of water resources) PF, equity (delivery of fair amount) $\mathrm{PE}$ and dependability (uniform delivery over time) PD are evaluated to dig out both spatial and temporal variations of discharge. From the computed performance indicator values, performance was classified as "good," "fair," or "poor" according to performance standards given by [18].

\subsubsection{Adequacy (PA)}

Adequacy is the ability of an irrigation system to meet the required irrigation water. The indicators were assessed for nine measuring reaches of the canal for head, middle and tail reaches for one irrigation season from October to December. The average spatial and temporal values of discharge at each 
selected off take was determined and the result is shown in table 3 and figure 9.

Table 3. Estimated values of required $(Q R)$ and delivered flow $(Q D)$.

\begin{tabular}{|c|c|c|c|c|c|}
\hline \multirow{3}{*}{ Reach } & \multicolumn{5}{|l|}{ Temporal } \\
\hline & Month & October & November & December & Mean \\
\hline & Off take & QD/QR & QD/QR & QD/QR & QD/QR \\
\hline \multirow{5}{*}{ Head } & TO1 & 1 & 0.81 & 0.95 & 0.92 \\
\hline & TO2 & 1 & 0.50 & 1.00 & 0.83 \\
\hline & TO3 & 1 & 0.12 & 1.00 & 0.71 \\
\hline & Mean & 1 & 0.48 & 0.98 & 0.82 \\
\hline & TO4 & 1 & 0.19 & 0.31 & 0.50 \\
\hline \multirow[t]{4}{*}{ Middle } & TO5 & 1 & 0.40 & 1.00 & 0.80 \\
\hline & TO6 & 0.61 & 0.75 & 0.95 & 0.77 \\
\hline & Mean & 0.87 & 0.45 & 0.75 & 0.69 \\
\hline & TO7 & 0.86 & 0.08 & 0.91 & 0.62 \\
\hline \multirow[t]{4}{*}{ Tail } & TO8 & 0.03 & 0.58 & 0.73 & 0.45 \\
\hline & TO9 & 1 & 0.77 & 0.44 & 0.74 \\
\hline & Mean & 0.63 & 0.48 & 0.69 & 0.60 \\
\hline & Spatial Mean & 0.83 & 0.47 & 0.81 & 0.70 \\
\hline
\end{tabular}

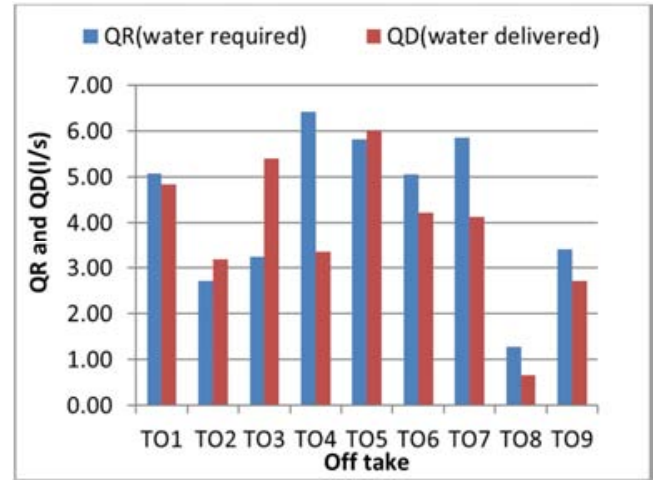

Figure 8. Temporal average values of required and delivered flow.

Average special and temporal values of adequacy are shown in Figure 9. (I, II \&III) with an average value of $0.83,0.47$ and 0.81 in October, November and December, and $0.82,0.69$ and 0.60 at head middle and tail reach of the system respectively.
However, the overall adequacy value of the system is found in the range of poor with the mean value of 0.70 . Due to the fact that, the PA performance criteria suggested by [18]. The spatial and temporal average adequacy of the scheme is poor except the head reach of the distribution system. The temporal adequacy in the head reach falls in the faire range. However, the overall average adequacy level during the season for the entire command of the main canal is found to be poor.

The major common problems of the system were unknown volume of water delivery and Irregular scheduling, weak management of the committee to operate the system according to the delivery schedules, people use the river for domestic purpose, sedimentation of canals, and inadequacy operation of the physical system components due to scant maintenance work. These factors influence the required benefits of the system. According to [15] derived similar results study on the performance.

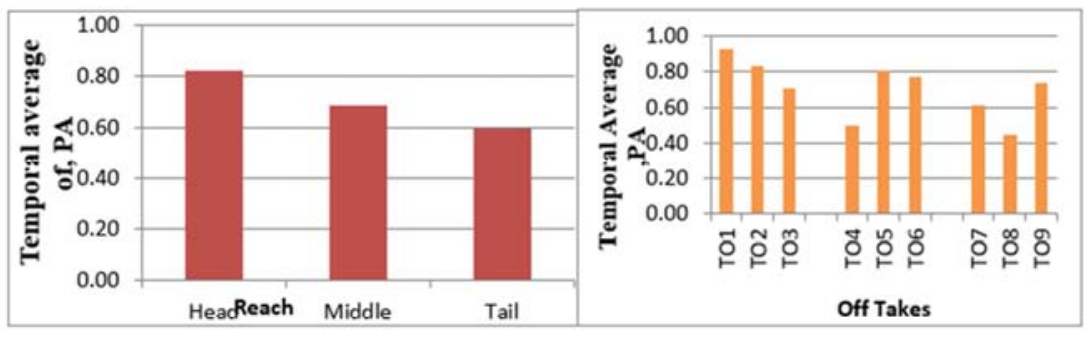

I) temporal average of PA in reaches

II) Temporal of PA in the Tertiary off take

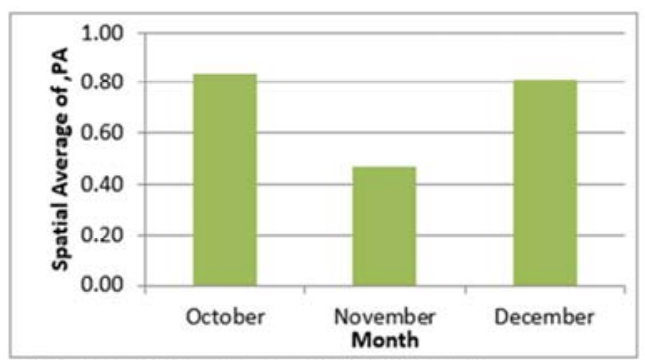

III) Spatial average of PA in the month

Figure 9. Spatial and temporal average adequacy over month and reach wise. 


\subsubsection{Equity (PE)}

Equity is the spatial coefficient of variation of the water delivery performance indicator. Equity of water distribution was calculated as the coefficient of variation of the adequacy values between locations. The degree of spatial variation of water delivery performance for all off take location over 3 months is presented in table 4. and Figure 10.

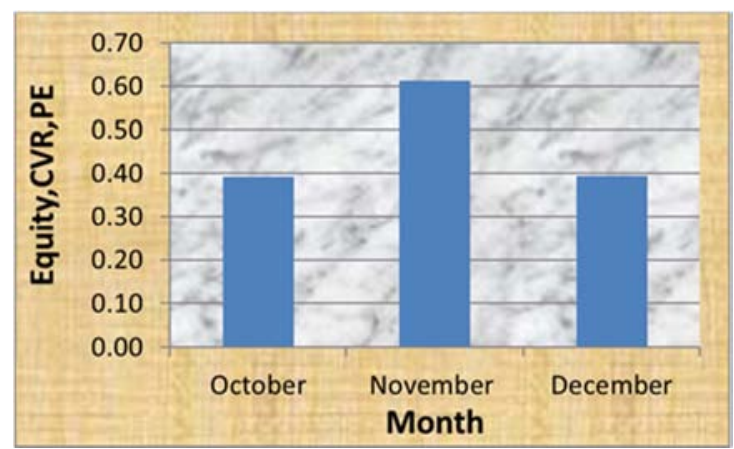

Figure 10. Average Equity of water distribution in the irrigation system during the month.

As illustrated the result in Figure 10 equity of water distribution during October November and December was Fair, Poor and poor its value found to be $0.14,0.33$ and 0.48 . According to water delivery performance standards given by [18] the spatial distribution of water in the canal during the month of October was fair. Therefore, it decided that, in these months, the spatial coefficient of variation of adequacy between the off takes is unbiased. In November and December, the PE as spatial distribution of water in the canal was poor. This shows that, when those supplies were free, some of the canals received more than their needs and some received less.

\subsubsection{Dependability}

Dependability of water supply is the temporal uniformity of the ratio of the delivered amount of water to the required amount. The measurement indicates the degree of temporal variability in the ratio of amount delivered to the required over a region. The indicator enables us to answer the question outlined on: does the timing of the water deliveries match the growth needs of the crops and the expectations of the users? [19]. The parameter was computed as the coefficient of variation of the adequacy values for individual locations of the system reaches over different time periods using Equation (9). The result of dependability is presented in table 4 and Figure 11. (a \&b).

The average dependability values of head, middle and tail reach of a system are ranging from 0.39 to 0.65 with an overall average dependability of 0.53 . The temporal average coefficient of variation (PD) is given in Figure 11. a and b. accordingly, the dependability of water distribution in Gatto irrigation scheme at head, middle and tail reaches are poor $(>0.20)$, Since, the performance of the entire system (Table 4) in terms of dependability of water distribution is found to be in the range of unsatisfactory.

Table 4. Dependability of water supplied and Equity of water distribution on the system.

\begin{tabular}{|c|c|c|c|c|c|c|c|c|c|c|c|c|}
\hline & \multicolumn{3}{|l|}{ Head } & \multicolumn{2}{|l|}{ Middle } & \multicolumn{4}{|l|}{ Tail } & \multirow{3}{*}{ Sp.ave } & \multirow{3}{*}{ STD } & \multirow{3}{*}{ CVR,PE } \\
\hline & T01 & TO2 & TO3 & TO4 & TO5 & TO6 & TO7 & TO8 & TO9 & & & \\
\hline & QD/QR & QD/QR & QD/QR & QD/QR & QD/QR & QD/QR & QD/QR & QD/QR & QD/QR & & & \\
\hline \multicolumn{13}{|l|}{ Month } \\
\hline Oct. & 1.00 & 1.00 & 1.00 & 1.00 & 1.00 & 0.62 & 0.86 & 0.03 & 1.00 & 0.83 & 0.33 & 0.39 \\
\hline Nov. & 0.81 & 0.50 & 0.12 & 0.19 & 0.41 & 0.75 & 0.08 & 0.57 & 0.77 & 0.47 & 0.29 & 0.61 \\
\hline Dec. & 1.00 & 1.00 & 1.00 & 0.31 & 0.37 & 0.95 & 0.91 & 0.73 & 0.44 & 0.75 & 0.29 & 0.38 \\
\hline Temp. & 0.94 & 0.83 & 0.71 & 0.50 & 0.59 & 0.77 & 0.62 & 0.44 & 0.74 & 0.68 & 0.30 & 0.44 \\
\hline Std. & 0.11 & 0.29 & 0.51 & 0.44 & 0.35 & 0.17 & 0.47 & 0.37 & 0.28 & & & \\
\hline CVT,PD & 0.11 & 0.35 & 0.72 & 0.87 & 0.59 & 0.21 & 0.75 & 0.83 & 0.38 & & & \\
\hline Av.PD & & & 0.39 & & 0.56 & & 0.65 & & & 0.53 & & \\
\hline
\end{tabular}
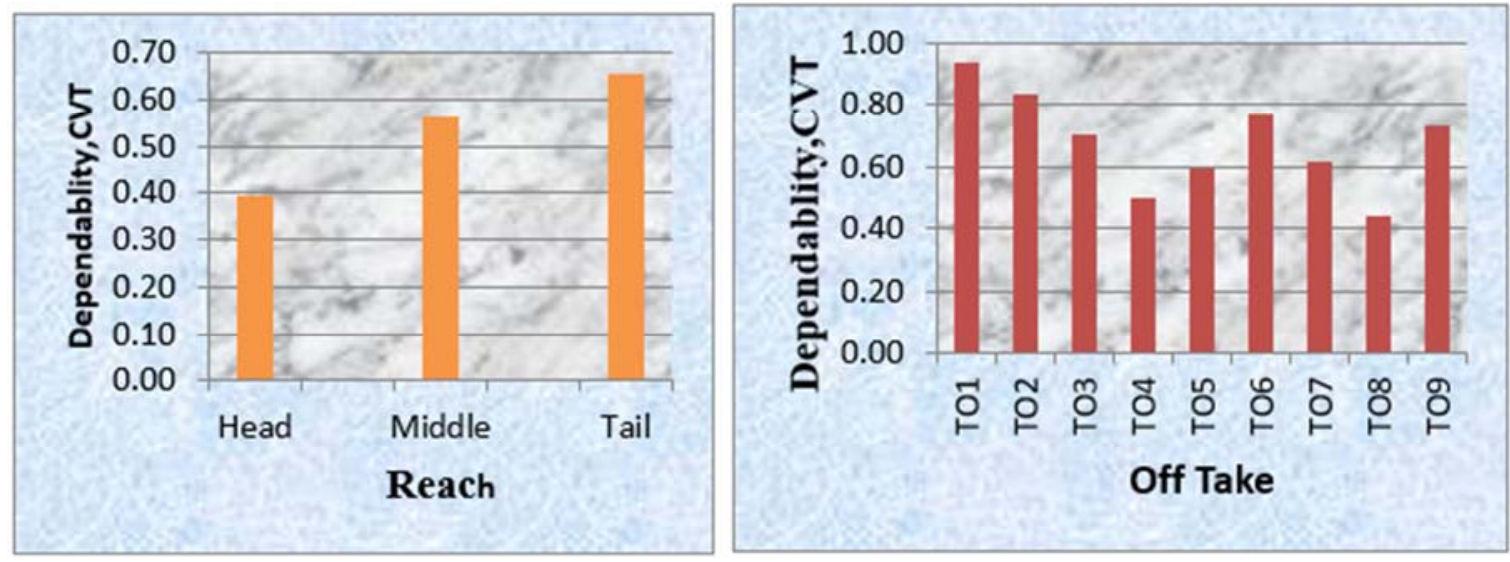

a) Average PD value in the reach b) Average of PD in the Tertiary off take

Figure 11. Average dependability of water distribution in the reach and off take canal. 


\subsubsection{Efficiency (PF)}

Efficiency is the measure of the excess of water delivered to the canal off take in comparison with the requirements. $\mathrm{PF}$ is the inverse of adequacy which was calculated by the Equation (10). The average spatial values for the irrigation season and average temporal values of reach wise and individual off take is shown on table 5. and figure 12. (a, b, c).

Table 5. Average Spatial and Temporal efficiency.

\begin{tabular}{|c|c|c|c|c|c|c|c|c|c|c|}
\hline & \multicolumn{3}{|l|}{ Head } & \multicolumn{3}{|l|}{ Middle } & \multicolumn{3}{|l|}{ Tail } & \multirow{3}{*}{ Spatial Av,PF } \\
\hline & TO1 & TO2 & TO3 & TO4 & TO5 & TO6 & TO7 & T08 & TO9 & \\
\hline & QR/QD & QR/QD & QR/QD & QR/QD & QR/QD & QR/QD & QR/QD & QR/QD & QR/QD & \\
\hline \multicolumn{11}{|l|}{ Month } \\
\hline Oct. & 0.90 & 0.86 & 0.70 & 0.55 & 0.69 & 1.00 & 1.00 & 1.00 & 0.52 & 0.80 \\
\hline Nov. & 1.00 & 1.00 & 1.00 & 1.00 & 1.00 & 1.00 & 1.00 & 1.00 & 1.00 & 1.00 \\
\hline Dec. & 1.00 & 0.63 & 0.36 & 1.00 & 0.87 & 1.00 & 1.00 & 1.00 & 1.00 & 0.87 \\
\hline Temp.ave & 0.97 & 0.83 & 0.69 & 0.85 & 0.85 & 1.00 & 1.00 & 1.00 & 0.84 & \\
\hline $\mathrm{PF}, \mathrm{Av}$ & & 0.83 & & 0.90 & & & 0.95 & & & 0.89 \\
\hline
\end{tabular}

The result shows that the average spatial value of efficiency for the month October, November and December are $0.80,1.00$, and 0.87 . Regarding the average temporal values of efficiency at head, middle and tail reach are 0.83 , $0.90,0.95$ consecutively. From this value the spatial mean value of efficiency was categorize fair, good, good and also fair, fair on October and December, good on November respectively and all are under good temporally except fair on head. Even though the efficiency fall under category of fair, good, good temporally or reach wise (head, middle and tail) The same result was also obtained by [23] from the study conducted on Wonji-Showa large-scale irrigation scheme.

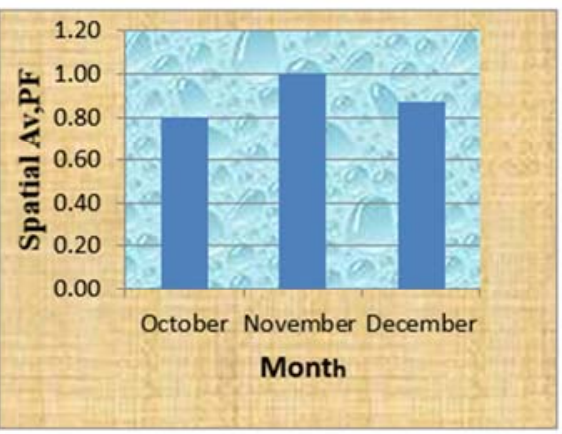

a) Spatial average of $\mathrm{PF}$ in the month

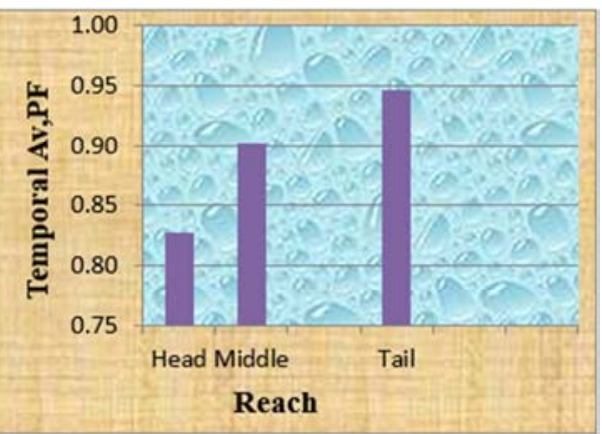

b) Temporal Average of $\mathrm{PF}$ in the reach

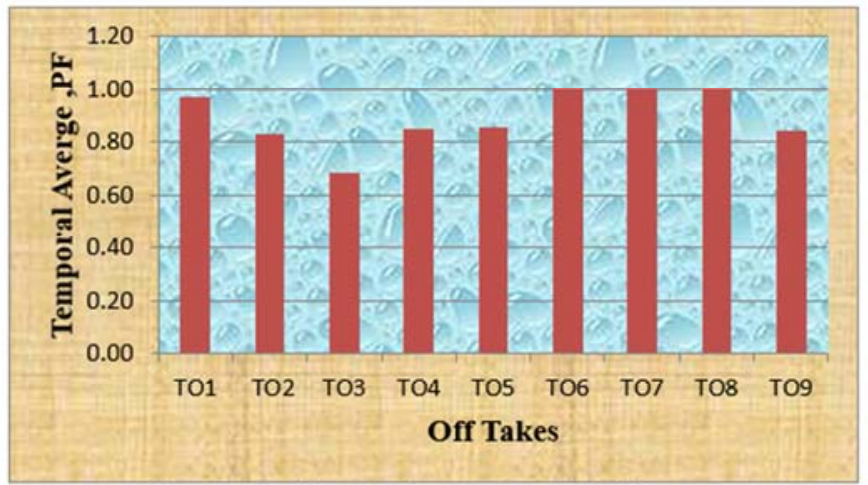

c) Temporal average of PF in the Tertiary Off take

Figure 12. Average dependability of water distribution in the reach and off take canal.

\subsection{Conveyance Efficiency}

The average main canal and secondary canal conveyance efficiency and conveyance losses of the scheme were presented in Tables 5 and 6 and Figure 13 (a \& b) and figure 14 (a \& b). The lined main canal and secondary canal conveyance efficiency was estimated using automatic current meter measured discharges at the interval of $100 \mathrm{~m}$ for the main canal and $150 \mathrm{~m}$ for secondary canal.

\subsubsection{Main Canal Conveyance Efficiency}

The measured values of water conveyance efficiency varied from $73.0 \%$ to $92.24 \%$. The conveyance efficiencies were different for each canal section. The values for the main canal were different from head to tail of the scheme because water flow in canal network was not uniform. The highest 
conveyance efficiency of the main canal was $92.24 \%$ for a section of CP4 (300-400m) and the lower efficiency was $73.0 \%$ in the section CP9 $(800-900 \mathrm{~m})$. The overall value of the conveyance efficiency of the lined section of the main canal was $86.3 \%$ percent, which is less than [13] recommended value of $95 \%$ for lined main canal.

The average conveyance loss per 100-meter length of the main canal was varied between 0.91 to 4.62 . The highest value of conveyance loss indicated in section CP9 (800-900m) this the section needs maintenance as compared to other lined sections of main canal; however, it doesn't mean the other section of the canal will not get maintenance. The main reasons for these conveyance losses were; none functional of flow control gates, unauthorized water turnouts (breaching of main canals that leads leakage) and illegal water abstractions, and the peoples who lived around the main canal used canal water for domestic purpose; for washing their body and animals (goat, sheep), clothes and used the river for water supply purpose. This inefficient conveyance affected the equity of water distribution throughout the systems; particularly the tail users did not get their equitable share of water within the required time. Generally, the canal water conveyance efficiency of canal water is affected by different canal attributes, which are canal types and flow rate amounts.

Table 6. Estimated Main canal water conveyance efficiency and conveyance losses.

\begin{tabular}{|c|c|c|c|c|c|c|c|}
\hline The Main Canal Reaches & $\begin{array}{l}\text { Location } \\
\text { along canal }\end{array}$ & $\begin{array}{l}\text { Canal Section distance } \\
\text { from head end }(\mathrm{m})\end{array}$ & Q I (l/s) & Qo (l/s) & $\begin{array}{l}\text { Water conveyance } \\
\text { efficiency }(\%)\end{array}$ & loss $(\%)$ & loss $/ 100 \mathrm{~m}$ \\
\hline \multirow{5}{*}{ Head } & $\mathrm{CP} 1$ & $0-100$ & 73.34 & 60.12 & 81.97 & 18.03 & 13.22 \\
\hline & $\mathrm{CP} 2$ & $100-200$ & 60.12 & 53.12 & 88.36 & 11.64 & 3.50 \\
\hline & $\mathrm{CP} 3$ & $200-300$ & 53.12 & 48.72 & 91.71 & 8.29 & 2.20 \\
\hline & $\mathrm{CP} 4$ & $300-400$ & 48.72 & 44.94 & 92.24 & 7.76 & 1.89 \\
\hline & CP5 & $400-500$ & 44.94 & 40.36 & 89.80 & 10.20 & 2.29 \\
\hline \multirow[t]{2}{*}{ average } & & & & & 88.82 & 11.18 & 4.62 \\
\hline & CP6 & $500-600$ & 40.36 & 36.68 & 90.88 & 9.12 & 1.84 \\
\hline \multirow[t]{3}{*}{ Middle } & CP7 & $600-700$ & 36.68 & 33.54 & 91.45 & 8.55 & 1.57 \\
\hline & $\mathrm{CP} 8$ & $700-800$ & 33.54 & 30.21 & 90.08 & 9.92 & 1.66 \\
\hline & CP9 & $800-900$ & 30.21 & 22.06 & 73.00 & 27.00 & 4.08 \\
\hline \multirow[t]{2}{*}{ Average } & & & & & 86.35 & 13.65 & 2.29 \\
\hline & CP10 & $900-1000$ & 21.34 & 18.25 & 85.5 & 14.5 & 3.09 \\
\hline \multirow[t]{2}{*}{ Tail } & CP11 & $1000-1100$ & 18.25 & 15.34 & 84 & 16 & 2.91 \\
\hline & CP12 & $1100-1200$ & 15.34 & 12.53 & 81.7 & 18.3 & 2.81 \\
\hline Average & & & & & 83.74 & 9.01 & 0.91 \\
\hline Over All mean & & & & & 86.3 & 11.28 & 2.61 \\
\hline
\end{tabular}

Note: $\mathrm{CP}=$ Main canal control point; $1,2,3 \ldots \ldots 12$, and QI and QO measured discharge at first and second control points respectively.

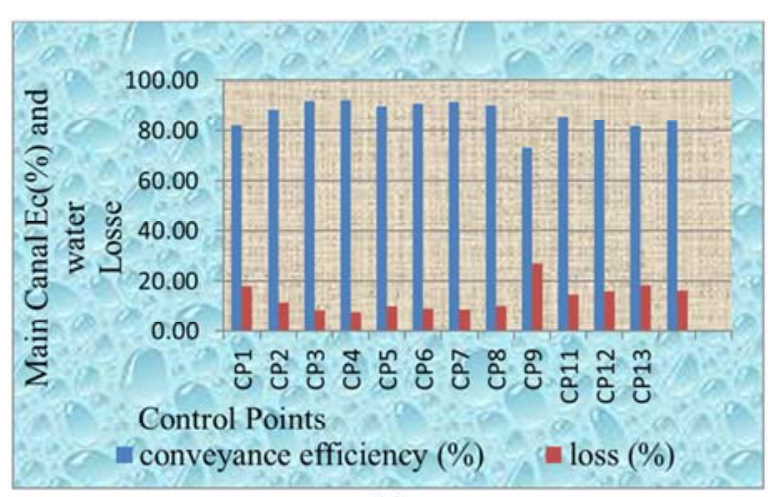

(a)

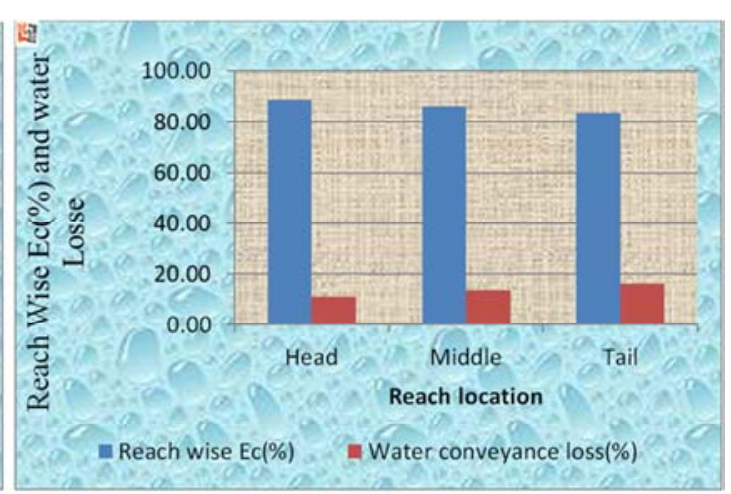

(b)

Figure 13. ( $a$ and b) Main canal and reach wise water conveyance efficiency (Ec) and water conveyance losses.

\subsubsection{Secondary Canal Conveyance Efficiency}

As indicated in table 6 , from 8 measurement control points, the Maximum and minimum conveyance efficiencies of secondary canal were $79.66 \%$ and $72.64 \%$ at observation point SC13 (300-450) $\mathrm{m}$ and SC15 (600-750) $\mathrm{m}$ and the average conveyance efficiency of secondary canal one (SC1) and secondary canal two (SC2) were $77.53 \%$ and $73.13 \%$, however the result found in the scheme was smaller than [13] recommended value $(90 \%)$ for unlined clay soil type.

This result shows that it needs an improvement in conveyance efficiency. This loss would likely have been much lower by lining the canals especially in areas where the seepage loss is very high in secondary canals and by constructing different canal structures like turn outs to decrease obstructing the flow of water by bund breaks, clods and trashes of grasses.

In this scheme the lost amounts per $150 \mathrm{~m}$ length was so high, but it was observable and actual at field conditions and the losses at secondary canals was higher than the main canal. Generally, the cause of reducing conveyance efficiency and the increasing of conveyance loss in the scheme has been seen due to: Spillage and Seepage losses, Canals have been silted with 
weeds and soils, Canals were crack and broken and most of the flow controlling structures are out of functional.

Table 7. Estimated Main canal water conveyance efficiency and conveyance losses.

\begin{tabular}{|c|c|c|c|c|c|c|c|}
\hline Sec. Canal & Distance (m) & Location along canal & Qi (1/s) & Qo(l/s) & Conveyance efficiency (\%) & Loss (\%) & loss $/ 100 \mathrm{~m}$ \\
\hline \multirow{5}{*}{$\mathrm{SC} 1$} & $0-150$ & SC11 & 16.55 & 13.02 & 78.71 & 21.29 & 3.52 \\
\hline & $150-300$ & $\mathrm{SC} 12$ & 13.02 & 10.13 & 77.80 & 22.20 & 1.45 \\
\hline & $300-450$ & $\mathrm{SC} 13$ & 10.13 & 8.07 & 79.66 & 20.34 & 1.03 \\
\hline & $450-600$ & SC14 & 8.07 & 6.36 & 78.81 & 21.19 & 0.86 \\
\hline & $600-750$ & $\mathrm{SC} 15$ & 6.36 & 4.62 & 72.64 & 27.36 & 0.87 \\
\hline average & & & & & 77.53 & 22.47 & 1.54 \\
\hline \multirow{4}{*}{$\mathrm{SC} 2$} & $750-900$ & $\mathrm{SC} 21$ & 16.76 & 12.57 & 75.00 & 25.00 & 2.10 \\
\hline & $900-1050$ & $\mathrm{SC} 22$ & 12.57 & 10.01 & 79.63 & 20.37 & 1.28 \\
\hline & $1050-1200$ & $\mathrm{SC} 23$ & 10.01 & 7.32 & 73.13 & 26.87 & 1.35 \\
\hline & & $\mathrm{SC} 24$ & 7.32 & 5.63 & 76.91 & 23.09 & 0.85 \\
\hline Average & & & & 8.88 & 76.17 & 23.83 & 1.39 \\
\hline
\end{tabular}

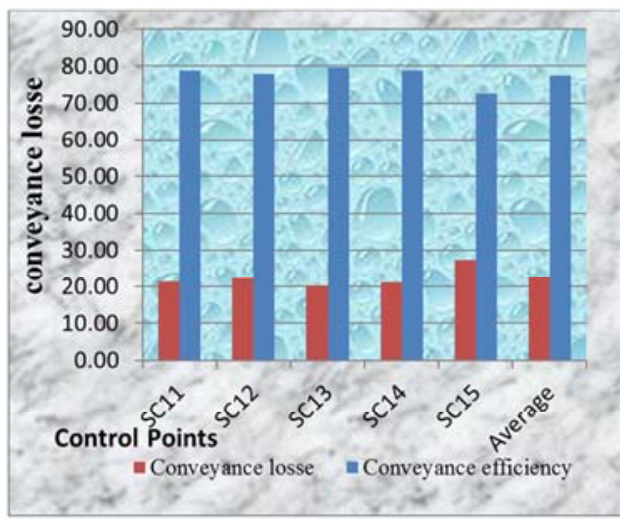

(a)

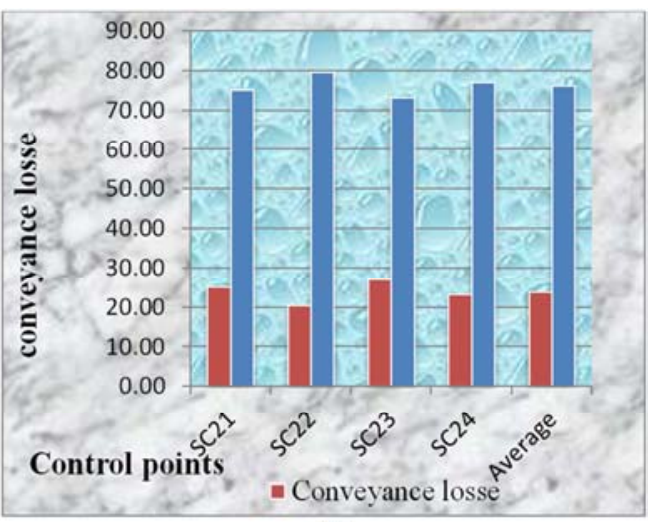

(b)

Figure 14. ( $a$ and b) Variation of water conveyance efficiency and water conveyance losses for secondary canal SC1 and SC2.

\subsection{Maintenance Indicators}

The maintenance indicator was assessed in terms of Relative change of water level, Effective of infrastructure, and sustainability of irrigation.

\subsubsection{Relative Change of Water Level}

Table 8. Estimated Main canal water conveyance efficiency and conveyance losses.

\begin{tabular}{llll}
\hline S. No. & Description & $\begin{array}{l}\text { Q in } \\
\mathbf{m}^{3} / \mathbf{s e c} .\end{array}$ & $\begin{array}{l}\text { H (depth of } \\
\text { water in } \mathbf{~ m})\end{array}$ \\
\hline 1 & Designed max value of the main canal & 1.24 & 0.42 \\
2 & Current max value of the main canal & 0.96 & 0.26 \\
3 & Change of values (0.42-0.26) & 0.28 & 0.16 \\
& Water delivery performance & & $38 . .1 \%$ \\
\hline
\end{tabular}

This is calculated as the ratio of change of the water level in the canal to the intended (designed) level. The design or intended value of the water level $(\mathrm{H})$ when the main canal carries a maximum discharge of $1240 \mathrm{lit} / \mathrm{second}$ was $0.42 \mathrm{~m}$. whereas when the discharge was $0.96 \mathrm{~m}^{3} / \mathrm{sec}$, the actual level (height) measured was $0.26 \mathrm{~m}$. This makes the value of relative change of water level to be 38.1 percent. This greater than 0 value indicates that the intended water level in the main canal has not been achieved due to sediment accumulation in the canal. Hence less discharge is delivered per unit time.

To overcome such shortfalls, farmers either should increase the irrigation time or otherwise under irrigate the fields. Increasing the irrigation time ultimately disturbs the irrigation schedule and creates water management problems that affect downstream farmers' irrigation scheduling with a concomitant conflict among beneficiaries.

\subsubsection{Effective of Infrastructure}

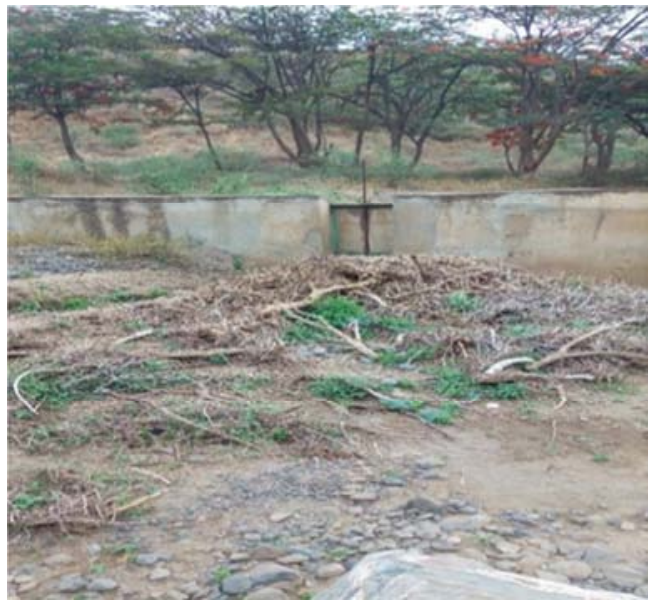

Figure 15. Malfunctioned structure in the scheme.

The effective of infrastructure stands for the ratio of the number of functioning structures to the total number of structures initially installed. Accordingly, in Gatto, the total numbers of different structure constructed were 14 but only 8 of them are functional. As a result, the value of Effective of Infrastructures is reckoned to be 57.2 percent. Many of the 
structures are demolished and became dysfunctional because of scouring, sedimentation and changing the original water way in the other direction to get the required amount of water for users.

\subsubsection{Sustainability of Irrigation}

In Gatto irrigation scheme, the potential net irrigable area was 200 ha, and the actual irrigated area during the study season was only 176 ha. This gives sustainability of irrigation scheme as $88 \%$ percent and the original irrigated land was reduced by $12 \%$ percent. These were happening due to flooding, natural drainage, and water shortage and soil fertility degradation. In the irrigation schemes flooding were happen and damages the farmer's field by loading stones on the field and affects the soil fertility. The flood erodes the fertile soil of the field and also it causes valleys that are not important for irrigation. This leads to reduction of irrigation area.

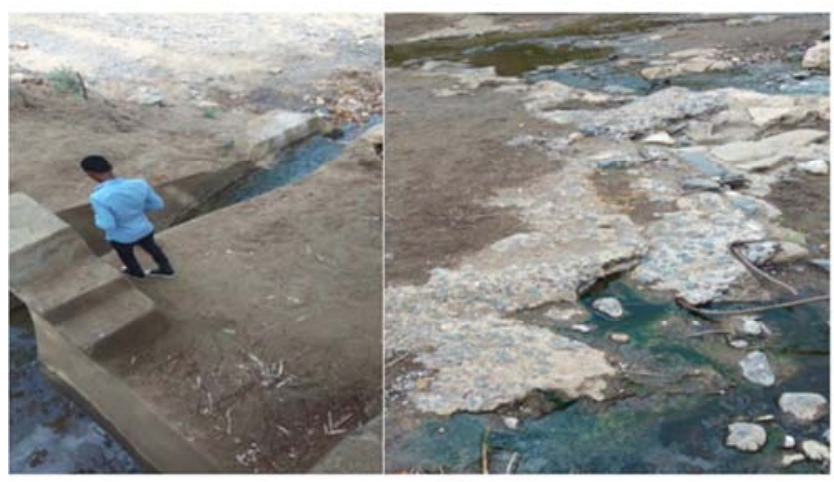

Figure 16. The flood erodes fertile land around bank of the cannel.

\subsection{Problems on Physical Structure}

\subsubsection{Diversion Weir and Ancillary Structures}

Based on field observation and inventory data of physical structures, there was significant default on the weir crest, wing wall and the intake gate had a problem during the operation time i.e. the gate rod had not easily movable during the closing and opening of the intake gate due to lack of oil grease and malfunctioned of the structure.
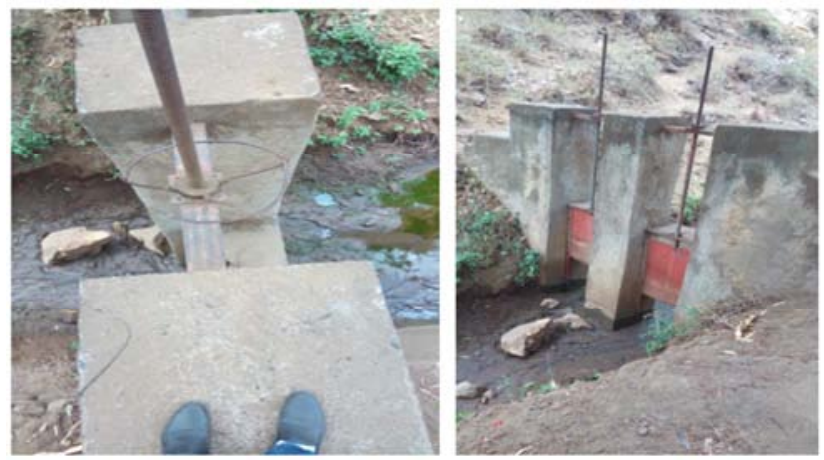

Figure 17. Malfunctioned flow regulator and present condition of the scheme.

\subsubsection{Cross Drainage Structures}

The structures, which were constructed to drain the erosion, had got a problem of embankment erosion i.e. the soils that support the cross drainage structure was severely eroded at its side as well as at its bed.

\subsubsection{Main Canal and Secondary Canal}

Main canal is a structure, which conveys water from the river to different parts of the scheme. The canal was Lined canal and its capacity decreased due to silting and sedimentation. At some part of the main canal, during the rainy season there was a great problem of scouring and siltation at the lower part of the canal. The secondary canals in Gatto irrigation scheme were unlined and mostly the water escapes by leaving its original direction during rainy season.
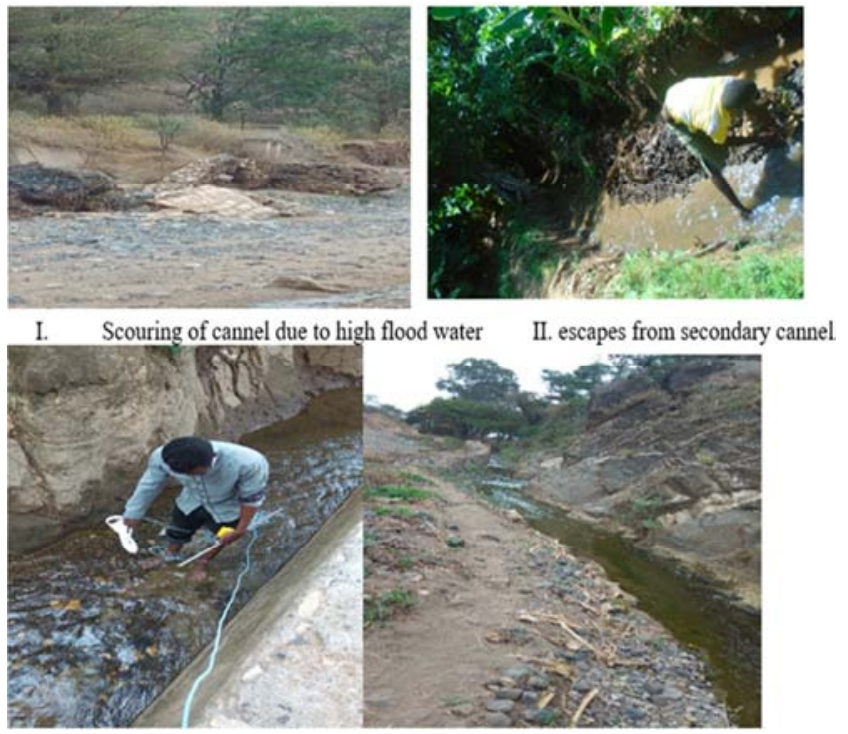

Figure 18. The present existence of cannel condition in the scheme.

Generally, a deviation of some structures would signal the need for maintenance or rehabilitation for flow control structures [5] The reason for this deviation may be due to canal siltation and sedimentation. In Gatto irrigation scheme practically the distribution was rotational implying that completing irrigation at one part of the system or individual farmers' field then the turn will be the next system or farmers.

According to [4] the purpose of maintenance is either to eliminate the cause of poor irrigation or drainage system performance or to prevent this from happening. In the first case proper monitoring is required, in the second a schedule is needed, indicating the maintenance activities and their planning. On the whole, proper maintenance is critical to the success of irrigation and drainage systems, and to ensure that the design and operational objectives set by designers, planners, investors and farmers are achieved.

The number of un functional structure is increasing in the future if there is no proper operation and maintenance of the scheme. Structures located in the irrigation system are unable to control irrigation water due to High flood scouring in rainy season, siltation and sedimentation in the cannel, there is insufficient operation and maintenance attention given to irrigation structures in the scheme, resulting in inefficient operation. 


\section{Conclusions}

Based on the applied methodology and results obtained, the following conclusions are drawn: -

In this study, an attempt was made to evaluate the water delivery performance of Gatto small scale irrigation schemes at Dherashe woreda, southern Regional State, using internal performance indicators. The internal performance indicators computed were conveyance efficiency, delivery performance indicators and maintenance indicators.

The poor performance of irrigation system has happened due to several factors the major reasons are; malfunctioning of flow control and distribution structures, inadequate maintenance of irrigation infrastructures, sedimentation of canals, improper operation of water delivery system, unfortunate irrigation scheduling, design failure of water distribution structures and over abstraction of water by upstream schemes. This unsatisfactory performance of irrigation system could be reducing the productivity of the farm and brings water related conflicts.

Generally, poor performance of the irrigation system is due to the following factors; unreliable water deliveries, poorly control and distribution system, inflexible irrigation planning, varied cropping pattern, lack of supportive training for irrigation water application and management, inadequate frequent maintenance, sediment accumulation, improper operation of water delivery system, and malfunctioning of flow control structures. Therefore, the result focuses to the government and other stakeholders in identifying suitable improvement approaches.

\section{Recommendations}

The following recommendations are given on the basis of the next research work on Gato Small Irrigation Schem: -

Water delivery systems between the head and tail reach is not uniform spatially; the head receives more water than the tail during the investigation period. Therefore, it suggested that, introducing a warabandi system of water allocation on water delivery system at the head and tail reach of the watercourse.

From the major problems of canal system observed during this study, seepages through earthen canals, leakages through lined canals and structures, siltation of canals, weed grow in the canal and on the branches, illegally broken canal for additional offtake and low water levels due to canal erosion are the main problems need attention by users, government and nongovernmental body.

The scheme had no flow measurement and flow controlling structure. So, to apply the exact amount of water based on crop water demand discharge measurement and discharge controlling structures should be redesigned and installed.

The water conveyance efficiency of the system is unsatisfactory; so, the canal system requires continuous supervision and maintenance action to protect them from growing weeds, silt deposition, breaching of the canal by illegal water users and animals.
The installed gates and structures constructed in irrigation system and on the head, work was used to balance and facilitated the water delivery system and have a great role in keeping irrigation system in good performance. In Gatto irrigation scheme, those structures and gates is need maintenance and Monitoring of the scheme.

\section{References}

[1] Aklilu, A. (2006). Assessment of irrigation system at Sille state farm, Ethiopia (MSc Thesis, Arba Minch, Ethiopia).

[2] Allen, R. G, Pereira, L. S., Raes, D. and Smith, M. (1998). Crop evapotranspiration guidelines for Computing Crop Water Requirments. Journal of FAO Irrigation and Drainage Systems, 56, NRMED. Rome, Italy, p300.

[3] Binoy, M. A., Varghese, S. and Paul, K. (2013). Paul Irrigation system assessment farmers and manager's view. International Journal ofEngineering Science and Innovative Technology (IJESIT), 2, Issue 2, Kothamangalam, India, p 148-159.

[4] Boss, M. G., Burton, M. A, and Molden, D. J. (2005). Irrigation and drainage performance assessment practical guidelines. Journalof Centre for Advanced Biomedical Imaging, 22, Wallingford, UK, p 28-59.

[5] Boss, M. G., Murray-Rust, D. H., Merry, D. J., Johnson, H. G and Snellen, W. B. (1994). Methodologies for assessing performance of irrigation and drainage management. Irrigation and Drainage System 7: 231-261.

[6] Boss, R. (2000). ICID Guidelines on Performance Assessment. Working Group on Performance Indicators and Benchmarking. Rme, Italy: Report on a Workshop 3 and 4 August 200. FAO.

[7] Cakmak, B., Beyribey, M., Yildırım, Y. E. and Kodal, S.. (2004). Benchmarking performance of irrigation schemes: a case study from Turkey. Journal of Irrigation and Drainage, Colombo, SriLanka, p 155-163.

[8] ChuZhendu. (2001). Report on Small-Scale Integrated Rural Development Project-Identification of Investment Oportunity. Small Scale Development Project in Upper Nille-Jari. Amhara Region, Ethiopia: FAO-SSC/SPFS.

[9] Cui. Y., Y. Li, Z. Mao, J. Lance and A. Musy,. (2004.). Strategies for Improving the Water Supply System in HCID, Upper Reaches of the yellow River Basin, China. Agricultural Engineering International: The CIGR Journal of Scientific Research and Development. 23 (2): 34-65.

[10] Dejen, Z. A. (2015). Hydraulic and operational performance of irrigation schemes in view of Water Saving and Sustainablity: Sugar esates and community managed schemes In Ethiopia. CRC Press/Balkema.

[11] Doorenbos, J., Kassam A. H., Bentvelsen C. L. M., Branscheid V., Plusjé J. M. G. A., Smith M., Uittenbogaard G. O and Van Der Wal H. K.,. (1986). Yield response to water. FAO Irrigation and Drainage Paper 33. FAO, Rome.

[12] FAO. (1985). Guidelines Land Evaluation for Irrigated Agriculture. FAO Soils Bulletin 55, Rome.

[13] FAO. (1989b). Irrigation water management and scheduling. Training manual. FAO, Rome. 
[14] Korkmaz, N. and Avci, M. (2012.). Evaluation of water delivery and irrigation performances at field level: The case of menemen Left Bank irrigation district in Turky. Indian Journal of Science and Technology, 5 (2), pp 2079-2089.

[15] Kuper, M. and Kijne, J. M.. (1992). Irrigation managment in th Fordwash branch command area South East Punjab, Pakistan. Journal of IWMI, Colombo, Sir Lanka.

[16] Mamuye, T. and Mekonnen, A., 2015. Hydraulic Performance Evaluation of Hare Communi Managed Irrigation Scheme, Southern, Ethiopia.

[17] Mohsen, A., Kiamura, Y. and Shimizu, K.. (2012). Assessment of irrigation practices at mainIrrigation Network in the Nile Delta. Internationa Journal of Biological, Veternary, Agricultural and Food Engineering, 16 (9). World Academy of Science. Engineering and Technology.

[18] Molden, D. J., \& Gates, T. K. (1990). Performance measures for evaluation of irrigationwater-water-deliverysystems. Journal of irrigationand drainage engineering, 116 (6).

[19] Ostrom, E. (1990). Governing the Commons: The Evolution of Institutions for Collective Action. Cambridge University Press Cambridge, UK.

[20] Rieser, A., Bonn, U., Hoynck, S. and Koln, F. (1998). Irrigation performance in Thailand, problems of monitoring and evaluation.

[21] Woldeab, Teshome. (2003). Irrigation Practices, State Intervention and Farmers' Life-Worlds in Drought -Prone Tigray; Ethiopa.

[22] Yusuf, K. (2004). Assessment of small scale irrigation using comparative performance indicators on two selected schemes in upper Awash River valley Unpublished master thesis,. Alemaya University, Ethiopia.
[23] Zeleke, A. (2015). Hydraulic and operational performance of irrigation schemes in view of of water saving and Sustainablity, sugar sate and community managed schemes, Ethiopia, $\mathrm{PhD}$ Dissertation WageningenUniversity, te Netherlands.

\section{Biography}

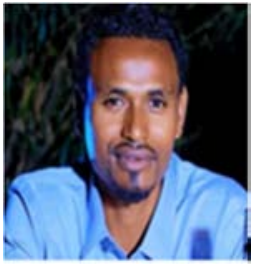

Tamirayehu Legesse, I acquired Bachelor degree in water Resources and Irrigation Engineering from Hawassa University. Arba Minch university employed me as Assistance lecturer at 2014G.C and in 2018 G.C. I hold my MSc. Degree in Irrigation and Drainage Engineering and still I am working at Arbaminch Water Technology Institute as senior Lecturer and I also done so many research papers in our Institute and collaborative research engagement for the community as well as the Institute itself.

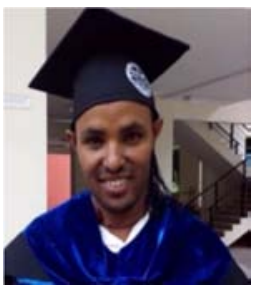

Amare Tadesse, I acquired Bachelor degree in water Resources and Irrigation Engineering from Hawassa University. Arba Minch university employed me as Assistance lecturer at 2014G.C and in 2017 G.C. I hold my MSc. degree in Hydraulic and Water Resources Engineering and still I am working at Arbaminch Water Technology Institute as senior Lecturer and I also done so many research papers in our Institute and collaborative research engagement for the community as well as the Institute itself. 